\title{
Advanced High-Lift Design by Numerical Methods and Wind Tunnel Verification within the European Project EUROLIFT II
}

\author{
Jochen Wild ${ }^{*}$ and Joel Brezillon ${ }^{\dagger}$ \\ DLR, Institute of Aerodynamics and Flow Technology, Braunschweig, 38162, Germany \\ Olivier Amoignon ${ }^{\ddagger}$ \\ FOI, Computational Physics Department, Stockholm, SE-164 90, Sweden \\ Jürgen Quest ${ }^{\S}$ \\ ETW European Transonic Windtunnel GmbH, Köln, 51147, Germany \\ Frederic Moens ${ }^{* *}$ \\ ONERA, Applied Aerodynamics Department, Châtillon, 92322, France \\ and \\ Domenico Quagliarella ${ }^{\dagger}$ \\ CIRA, Applied Aerodynamics Laboratory, Capua, 81043, Italy
}

\begin{abstract}
The design activity within the European $6^{\text {th }}$ framework project EUROLIFT II is targeted towards an improvement of the take-off performance of a generic transport aircraft configuration by a redesign of the trailing edge flap. The involved partners applied different optimization strategies as well as different types of flow solvers in order to cover a wide range of possible approaches for aerodynamic design optimization. The optimization results obtained by the different partners have been cross-calculated in order to eliminate solver dependencies and to identify the best obtained design. The final selected design has been applied to the wind tunnel model and the test in the European Transonic Wind Tunnel (ETW) at high Reynolds number confirms the predicted improvements.
\end{abstract}

\footnotetext{
${ }^{*}$ Research Scientist, Transport Aircraft Department

${ }^{\dagger}$ Research Scientist, Numerical Methods Department

* Research Engineer

$\S$ Chief Aerodynamicist, Senior AIAA member

${ }^{* *}$ Research Engineer

${ }^{\dagger}$ Research Engineer
} 


\section{Nomenclature}

\begin{tabular}{|c|c|c|c|}
\hline$\underline{\text { Latin }}$ & & $\eta$ & dimensionless wing span $\eta=2 y / b$ \\
\hline$C_{D}$ & $=$ drag coefficient & $\Lambda$ & wing aspect ratio \\
\hline$C_{L}$ & $=$ lift coefficient & $\tilde{\Lambda}$ & transformed wing aspect ratio \\
\hline$C_{L, \max }$ & $=$ maximum lift coefficient & $\varphi$ & wing sweep angle \\
\hline$c$ & $=$ local wing chord & \multicolumn{2}{|l|}{$\underline{\text { Subscripts }}$} \\
\hline$c_{p}$ & $=$ local pressure coefficient & ini $=$ & initial calculation \\
\hline $\begin{array}{l}D \\
F_{o b j}\end{array}$ & $\begin{array}{l}=\text { drag force } \\
=\text { objective function }\end{array}$ & $2 \mathrm{D}$ & $\begin{array}{l}\text { two-dimensional flow (leading edge } \\
\text { normalization) }\end{array}$ \\
\hline$F_{i}$ & $=$ objective function of design point $i$ & $2.5 \mathrm{D}$ & infinite swept wing flow \\
\hline$L$ & $=$ lift force & $3 \mathrm{D}$ & three-dimensional flow \\
\hline$M$ & $=$ Mach number & $\infty$ & flow conditions at infinity \\
\hline$P$ & $=$ penalty function & & \\
\hline$p$ & $=$ static pressure & Abbreviation & \\
\hline$p_{t}$ & $=$ stagnation pressure & $\begin{array}{l}\text { A-D } \\
\text { CAD }\end{array}$ & $\begin{array}{l}=\text { Airbus Germany GmbH } \\
=\text { computer aided design }\end{array}$ \\
\hline $\mathrm{Sr} R e$ & $=$ Reynolds number & CFD & $=$ computational fluid dynamics \\
\hline$T$ & $=$ temperature & CIRA & $=$ Centro Italiano Ricerche \\
\hline$T_{t}$ & $=$ stagnation temperature & & Aerospaziali \\
\hline$V_{S}$ & $=$ stall speed & DLR & $\begin{aligned}= & \text { Deutsches Zentrum für Luft- und } \\
& \text { Raumfahrt in der Helmholtz- }\end{aligned}$ \\
\hline$w_{i}$ & $\begin{array}{l}=\text { weighting factor for the } i \text {-th design } \\
\text { point } \\
=\text { vector of design parameters }\end{array}$ & ETW & $\begin{array}{l}\text { Gemeinschaft e.V. } \\
\text { Guropean Transonic Windtunnel }\end{array}$ \\
\hline$x, y, z$ & $\begin{aligned}= & \text { Cartesian coordinates }(2 \mathrm{D}: \mathrm{x}-\text { chord, } \mathrm{y} \\
& - \text { up; } 3 \mathrm{D}: \mathrm{x}-\text { chord, } \mathrm{y}-\text { span, } \mathrm{z}-\text { up })\end{aligned}$ & $\begin{array}{l}\text { EUROLIFT } \\
\text { FAA }\end{array}$ & $\begin{array}{l}=\text { European High Lift Programme } \\
=\text { Federal Aviation Administration }\end{array}$ \\
\hline$x_{F}, y_{F}$ & $=$ flap positioning parameters & $\begin{array}{l}\text { FOI } \\
\text { ONERA }\end{array}$ & $\begin{array}{l}=\text { Swedish Defence Research Agency } \\
=\text { Office National d'Etudes et de }\end{array}$ \\
\hline$\underline{\text { Greek }}$ & & PSE & $\begin{aligned} & \text { Recherches Aérospatiales } \\
= & \text { parabolized stability equations }\end{aligned}$ \\
\hline $\begin{array}{l}\alpha \\
\gamma\end{array}$ & $\begin{array}{l}=\text { angle of attack } \\
=\text { glide or climb path angle }\end{array}$ & RANS & $\begin{aligned}= & \text { Reynolds-averaged Navier-Stokes } \\
& \text { equations }\end{aligned}$ \\
\hline$\gamma_{C_{L}}, \gamma_{C_{D}}$ & $\begin{aligned}= & \text { correlated scaling factors for } \\
& \text { aerodynamic force coefficients }\end{aligned}$ & TO1/TO2 & $=$ first $/$ second take-off setting \\
\hline
\end{tabular}

\section{Introduction}

The EUROLIFT II project, funded by the European Commission within the 6th framework program, is dedicated to the investigation of transport aircraft in high-lift configuration. It covers both numerical and experimental studies, mainly targeted towards validation of CFD for maximum lift prediction of such configurations. It is a follow up to the EUROLIFT project of the 5th framework program ${ }^{1}$. While in the former project a simplified wing-body high-lift configuration was investigated, the new project focuses on a more realistic configuration including engine nacelles, pylons, tracks and brackets. Additionally the next step is undertaken coming from analysis to design. Since it is a main aim of the project to deal with realistic configurations, this design will be done at a Reynolds number comparable to flight conditions of a real transport aircraft.

The design activity within the project is targeted towards an improvement of the aerodynamic properties of the KH3Y wind tunnel model configuration, which has already been used in EUROLIFT. The investigations mainly focus on an increased take-off performance by modifying the trailing edge flap both in shape and position. The design is mainly performed using numerical optimization methods for optimization of a specific wing section. The involved partners apply different optimization strategies as well as different types of flow solvers in order to cover a wide range of possible approaches for aerodynamic design optimization. The flow calculation methods range from an Euler-Boundary layer code to structured and unstructured RANS solvers either in 2D or 2.5D. For optimization 
also a lot of different strategies are used, including gradient based methods, simplex strategies, simulated annealing, evolutionary algorithms and last but not least an industrial best practice approach.

The design activity is split up in three phases related to verification, design and validation. At the beginning a verification phase is scheduled where a mandatory test case has been defined and optimized applying the available design strategies in order to assess the reliability and the limitations of the design process. In a next phase the design specification has been formulated taking into the account the results of the verification phase. This case is now optimized by the different partners by using their numerical optimization processes. Afterwards the different optimization results are cross-checked in order to identify the best obtained design. In the validation phase in the further proceeding of the project, the best design is applied to the three-dimensional wind-tunnel model and is measured in ETW at high Reynolds numbers close to real flight conditions.

The work share between the partners within the design task was constructed in order to assess as many different strategies as possible. For this reason the different partners apply different optimization strategies as well as different levels of flow simulation accuracy. The optimization strategies applied include gradient based methods, simplex strategies and evolutionary algorithms. For the flow calculations Euler-boundary layer coupling methods (EulerBL), RANS methods and additionally parabolized stability equation methods (PSE) for transition prediction are used.

\section{Mandatory test case calculations}

The aim of this activity was to demonstrate the optimization capabilities by each partner and to ensure that the tools are available and applicable for the further work of task 2.2.

\section{A. Optimization case definition}

The selected design case was extracted from wind tunnel data obtained in the EUROLIFT (I) project, so that a correlation of numerically detected optimum and experimental data has been possible. The optimisation problem considered here is a multi-point design for the wing section of a landing configuration. Three main objectives are active when dealing with a landing configuration:

1. High maximum lift coefficients for low approach speeds and/or high aircraft capacity

2. Attached flow in the complete flight regime.

3. High $L / D$ at $1.13 V_{S}$, since the landing configuration is also used for noise classification where overflow heights at the microphone location are maximal.

These objectives are translated into an objective function by

$$
\begin{aligned}
F_{o b j}(\boldsymbol{x}) & =\sum_{i=1}^{3} w_{i} \cdot F_{i}(\boldsymbol{x}) \\
F_{1}(\boldsymbol{x}) & =-C_{L, \max } \\
F_{2}(\boldsymbol{x}) & =-\left.C_{L}\right|_{\alpha=0^{\circ}} \\
F_{3}(\boldsymbol{x}) & =-\frac{C_{L}}{C_{D}+\frac{C_{L}^{2}}{\pi \Lambda}}, C_{L}=C_{L, \max } / 1.13^{2}, \Lambda=9.353
\end{aligned}
$$

with $\boldsymbol{x}^{T}=\left(\Delta x_{F}, \Delta y_{F}\right)$ and $w_{1}=0.6, w_{2}=0.3, w_{3}=0.1$. The three design points are defined as follows:

1. $M_{\infty}=0.15, R e_{\infty}=700000, \alpha=$ free

2. $M_{\infty}=0.22, R e_{\infty}=1000000, \alpha=0^{\circ}$

3. $M_{\infty}=0.17, \operatorname{Re}_{\infty}=800000, \alpha=f\left(C_{L}\right)$

Two constraints should be applied:

1. $C_{L, \max } \geq C_{L, \max , i n i}$ for the first design point;

2. $C_{L}=C_{L \text { target }} \pm 0.001$ for the third design point.

The geometry used is the wing section of the KH3Y model of EUROLIFT (I) in landing configuration (TC214) at the location of the pressure row named DV06 at the non-dimensional span of $\eta=0.66$ (Figure 1). For further identification this test case is named TC301. 


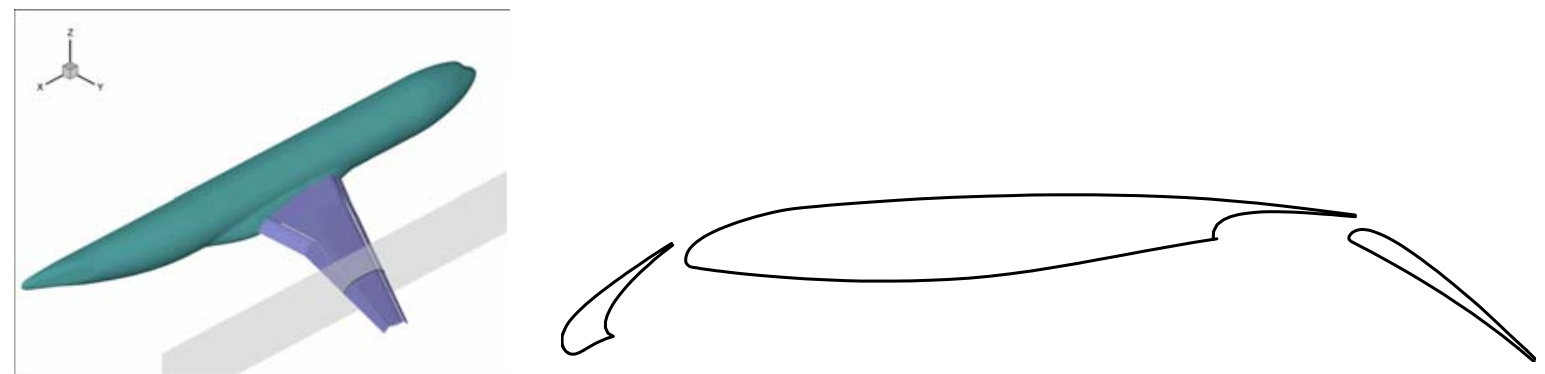

Figure 1. Wing section of the KH3Y model in landing configuration at the location of pressure row DV06

\section{B. Applied methods}

The applied methods for CFD simulation and numerical optimization cover the complete range of state-of-the-art for aerodynamic simulation and design. Gradient based, gradient free and stochastic optimization algorithms are incorporated. For CFD calculations most of the partners applied Finite Volume Methods based on the Reynoldsaveraged Navier-Stokes (RANS) equations. The equations are solved by a time-integration scheme. One partner applied within the optimization loop an Euler-boundary layer coupling method.

Table 1 summarizes briefly the methods used by the involved partners. A-D used the unstructured RANS flow solver TAU, developed by $\mathrm{DLR}^{2}$, in conjunction with an in-house unstructured mesh generator for 2D unstructured meshes. CIRA applied the well known Euler-boundary layer coupling flow solver MSES ${ }^{3}$ in free transition mode. DLR used its in-house developed FLOWer code $^{4}$, which is a structured finite-volume RANS solver. From several algebraic and transport turbulence equation models, the Spalart-Allmaras model with Edwards modification has been preferred for its accuracy and robustness. It was decided to generate new meshes at each optimization step applying the parametric grid generator MegaCads ${ }^{5}$ developed at DLR. All meshes are based on the same topology, a multi-block type mesh with 9 blocks, 90,065 points and designed for 3 levels of multigrid. FOI applied their flow solver $\mathrm{EDGE}^{6}$, which solves the Reynolds-averaged Navier-Stokes equations on unstructured grids. The SpalartAllmaras one-equation turbulence model is used here. Convergence is accelerated by local time stepping, multigrid, and implicit residual smoothing. Additionally, in order to account for natural transition a linear stability analysis is applied ${ }^{7}$. ONERA used for the calculation of the aerodynamic coefficients the ONERA elsA software ${ }^{8}$, which solves the compressible three-dimensional RANS equations by using a cell-centered finite volume spatial discretization on structured multi-block meshes. Computations have been carried out using an uncoupled approach between the RANS system and the turbulence model transport equations. The two-equation k- $\omega$ model from Wilcox ${ }^{9}$ with a wall function formulation ${ }^{10}$ has been selected for the optimization work, allowing $y^{+}$values around 100 and more regular cells is applied, since such modifications increase robustness and make high Reynolds number computations less mesh dependent. During the EUROLIFT I program, a comparison was made between classical structured multiblock, unstructured and structured chimera grids on the same configuration did not show dramatic differences ${ }^{11}$.

For the optimization all classes of strategies that exist today have been applied, including gradient-based, gradient-free and stochastic methods have been used. CIRA used a multi-objective genetic algorithm ${ }^{12,13}$ for the optimization, with a crossover rate of $100 \%$, a mutation rate of $1.5 \%$ and local random walk as selection method for choosing the mating parents. A-D applied a simulating annealing algorithm embedded into the PointerPro optimization framework provided by Synaps ${ }^{14}$. This tool allows for an easy definition of design parameters, and fuzzy logic can be used for target function definition. The user can take advantage of task wizards and visual programming tools. DLR used a well elaborated simplex method for this case due to the very limited number of design variables ${ }^{15}$. It is a subspace-searching simplex method for the unconstrained optimization of general multivariate functions that generalizes the Nelder-Mead simplex method. This method is well suited for optimizing

Table 1. Methods applied by the partners for the mandatory test case

\begin{tabular}{llll}
\hline \hline Partner & Solver type & Grid type & Optimization algorithm \\
\hline A-D & RANS & unstructured & simulated annealing \\
CIRA & Euler-BL & structured & genetic algorithm \\
DLR & RANS & structured & simplex algorithm \\
FOI & RANS & unstructured & quasi-Newton method \\
ONERA & RANS & structured & conjugate gradient \\
\hline \hline
\end{tabular}




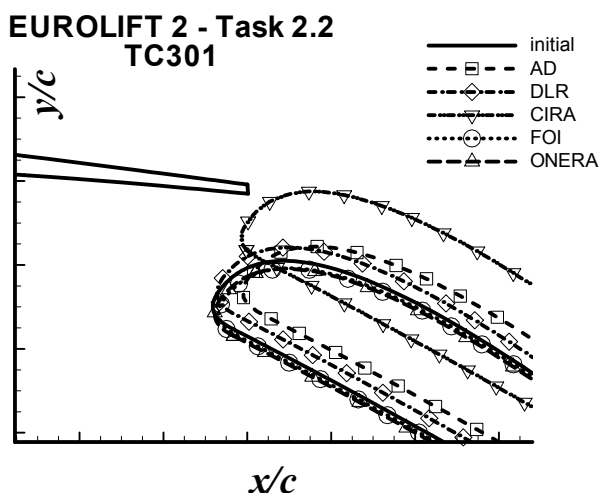

Figure 2. Optimized flap positions of the mandatory test case noisy functions, and, typically, the number of required function evaluations increases only with the problem size. FOI used a quasi-Newton method (BFGS update) to calculate descent directions in combination with a line search algorithm using Goldstein conditions ${ }^{16}$. The gradient of the objective function is estimated by a finite difference approximation, requiring in the present case 12 CFD solution for one gradient. ONERA applied the conjugate gradient method CONMIN of Vanderplaats ${ }^{17}$. In the present methodology the gradients are determined by finite differences at each iteration. For the accounting of the constraints, the feasible direction method of Zoutendijk is applied. The conjugation of the gradient is done according to Fletcher and Reeves. At each optimization iteration, three steps are performed to search for the objective function minimum along the search direction and to respect the constraints. The process for gradient computation has been parallelized, which means that in term of restitution time, the time requested of one optimization process is nearly equivalent to the number of iterations times the time needed for the flow solution.

Due to limitations of the applied CFD methods some partners had to modify the design case in order to be able to compute. The main limitation herewith had been the missing functionality of automatic determination of the maximum lift coefficient. This functionality is included only into the flow solver of DLR. A-D uses for this purpose an external process chain that determines maximum lift coefficient by a sequence of flow calculations while varying the angle of attack. CIRA and ONERA tackled this by using the angle of attack for the first design point as a design variable, which should lead to the maximum obtainable lift for the finally optimized configuration, but not for the initial one. FOI used a sequence of four CFD calculations and an L5-norm to estimate the maximum lift coefficient.

Additional adaptations to the design problem have been made by

- $\quad$ CIRA, to compute the second design point at $\alpha=2^{\circ}$ due to convergence problems at $\alpha=0^{\circ}$;

- $\quad$ FOI, to not use second design point in the optimization due to convergence problems and to omit the third design point in gradient computation;

- ONERA, to calculate the third design point at a constant angle of attack $\left(\alpha=10^{\circ}\right)$ instead of a target lift computation.

\section{Results}

All partners delivered their optimization results including:

- aerodynamic coefficients, surface pressure distributions and flow fields of the initial and optimized configuration;

- $\quad$ history of optimization in terms of design variables, aerodynamic coefficients, single objectives, global objective;

- $\quad$ optimization statistics in terms of number of needed CFD calculations, CPU-time and turn-around (wall clock) time.

Figure 2 shows the results of the flap position optimizations for each partner. It is obvious that the bandwidth of the results is very large. Only the results of FOI and ONERA are close to each other. These both results show a slight increase in flap gap while all other show a gap reduction. The vertical displacement of the A-D and DLR
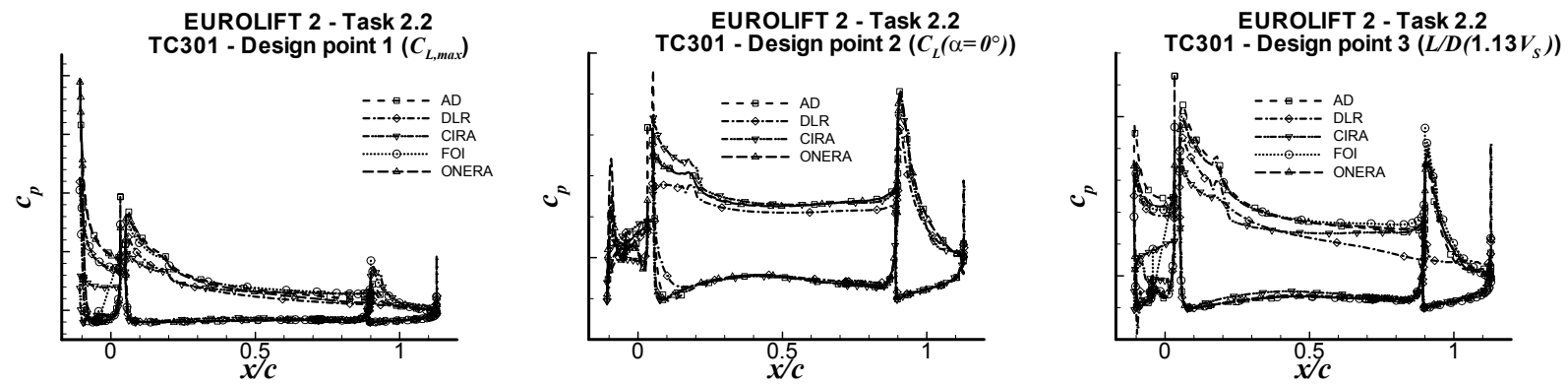

Figure 3. Comparison of the pressure distributions of the initial configuration calculated by the different partners 

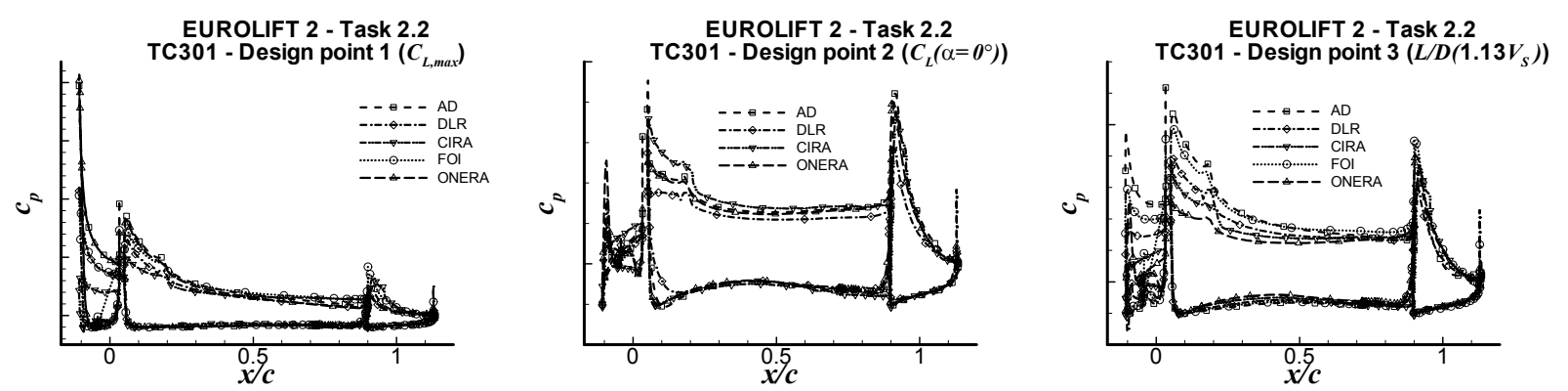

Figure 4. Comparison of the pressure distributions of the optimum configuration calculated by the different partners

result are nearly identical, but the A-D result is located more downstream. The result of CIRA is the one that is the most off of the others.

A detailed comparison of the provided data showed that already the calculations of the initial configuration show big differences among the partners. Figure 3 shows the pressure distributions for the initial configuration for each of the three design points. A similar spreading is observed for the optimized configurations (Figure 4). Comparing each of the partners results separately shows that the predicted improvements are reasonable related to the physics indicated by the flow field of the baseline configuration. Very significant for the optimization results using the RANS methods is the detection of a flap separation for the initial configuration (A-D, DLR) or attached flap flow (FOI, ONERA). Due to this flow feature the flap gap is reduced for the first to eliminate the flap separation, while the gap is increased for the second in order to further increase maximum lift. The CIRA results are mainly identified to be dependent on the calculation method (Euler-BL), which is known to poorly simulate the flap boundary layer interaction with the wake. Additional investigations by CIRA with their in-house RANS CFD-code verified the misleading sensitivity of the Euler-BL calculations for this type of flow field.

\section{Lessons learnt}

From the results obtained from this mandatory design task the main conclusions drawn are:

- all partners have their optimization environments running;

- different optimization results are related to differences in the flow for the initial configuration;

- better definition of initial configuration needed;

- usage of $C_{L, \max }$ in optimization is difficult to compare (only two partners have the possibility to directly detect $C_{L, \max }$, others use $\alpha$ as design variable);

- detection of flap separation is critical and strongly solver dependent;

- evaluate usability of Euler-BL solver on initial configuration in comparison with RANS method depending on the properties of the flow.

These conclusions directed the following guide lines for the definition of the flap design specification:

- clearly define the initial configuration in more detail than with flow conditions only;

- don't use $C_{L, \max }$ directly for optimization, since capabilities are not commonly available;

- avoid flow fields with the chance of massive flap separation because of strong solver dependencies.

\section{KH3Y flap design optimization}

The aim of this activity was to apply the numerical optimization capabilities of each partner for an improvement of the take-off performance of the KH3Y configuration by redesign of the flap. It was targeted to perform a multipoint design for the take-off configuration. Two main objectives are present:

Reduce drag for an improved climb performance.

Maintain or increase lift coefficients for lower take-off speeds and therefore reduced take-off field length.

\section{E. Optimization case definition}

The baseline of the design study is the DV06 wing section of the KH3Y model, now in take-off configuration (TC216), as measured in the ETW wind tunnel in the EUROLIFT (I) project (Figure 5). The coordinates have been provided both in stream wise coordinates and with leading edge sweep normalization applied ${ }^{18}$. The reference setting is the fixed TO2 setting with the flap deflected $22^{\circ}$ and the slat deflected $20^{\circ}$. The DV06 wing section was chosen, since it is in the middle of the outer wing part and between the slat and flap brackets, so 2D assumptions are most likely to be applied. 

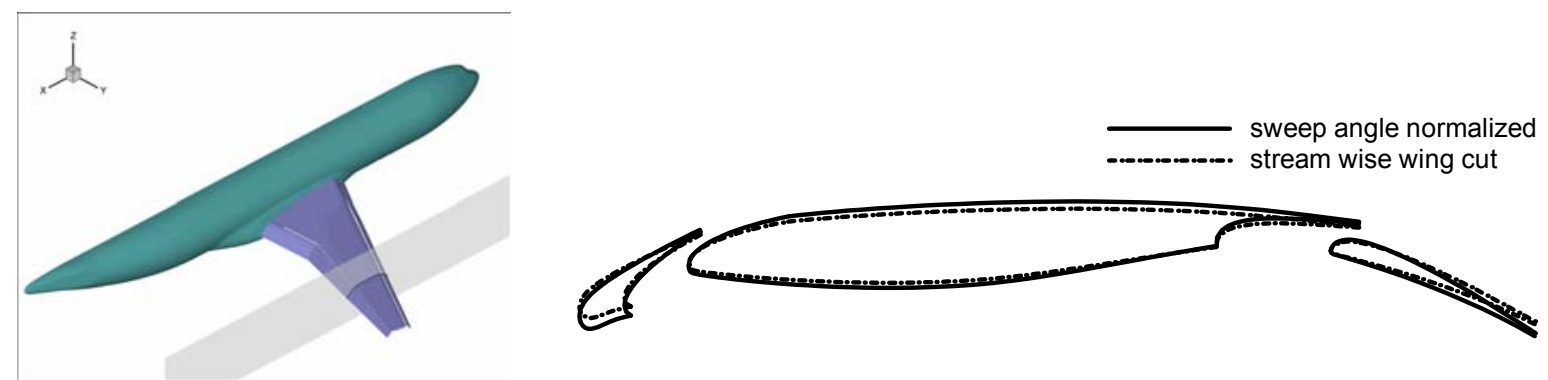

Figure 5. Wing section of the KH3Y model in take-off configuration (TO2) at the location of pressure row DV06 in stream wise and normalized coordinates.

Table 2. Correlation of flow conditions for comparable flow between 3D experiment and 2D/2.5D calculation

\begin{tabular}{lllll}
\hline \hline & & $3 \mathrm{D}$ & $2.5 \mathrm{D}$ & $2 \mathrm{D}$ (norm.) \\
\hline Design point 1 & $\mathrm{M}$ & 0.2 & 0.2 & 0.17146 \\
(upper limit) & $\mathrm{Re}$ & $15 \times 10^{6}$ & $15 \times 10^{6}$ & $11.03 \times 10^{6}$ \\
& & 8.00 & 8.25 & 9.599 \\
& $\mathrm{C}_{\mathrm{L}}$ & 1.69235 & 2.01694 & 2.74425 \\
\hline Design point 2 & $\mathrm{M}$ & 0.2 & 0.2 & 0.17146 \\
(lower limit) & $\mathrm{Re}$ & $15 \times 10^{6}$ & $15 \times 10^{6}$ & $11.03 \times 10^{6}$ \\
& & 11.91 & 12.75 & 14.785 \\
& $\mathrm{C}_{\mathrm{L}}$ & 2.05364 & 2.40691 & 3.27484 \\
\hline \hline
\end{tabular}

Due to the difficulties encountered at the mandatory test case optimizations, the description of the optimization problem for the flap design was specified much more carefully and additionally with respect to the behaviour of the $3 \mathrm{D}$ model wing examined in the previous wind tunnel experiments.

The design range is limited by two design points, depicted in Figure 6 , the first at $1.13 V_{S}$ of the take-off $22 / 20$ (TO2) setting, which is the minimum allowable speed. The second design point is at $1.13 V_{S}$ of the take-off $16 / 8$ (TO1) setting, which is the minimum speed for this setting, and therefore the speed where the setting will be changed from the TO2 setting to the TO1 setting. These two design points cover the complete flight range according to FAA airworthiness regulations ${ }^{19}$.

In order to obtain comparable results the flow conditions for the $2 \mathrm{D}$ calculations have been adjusted in order to match the pressure distributions of the initial configuration. An analysis made by DLR gives corresponding 2D flow

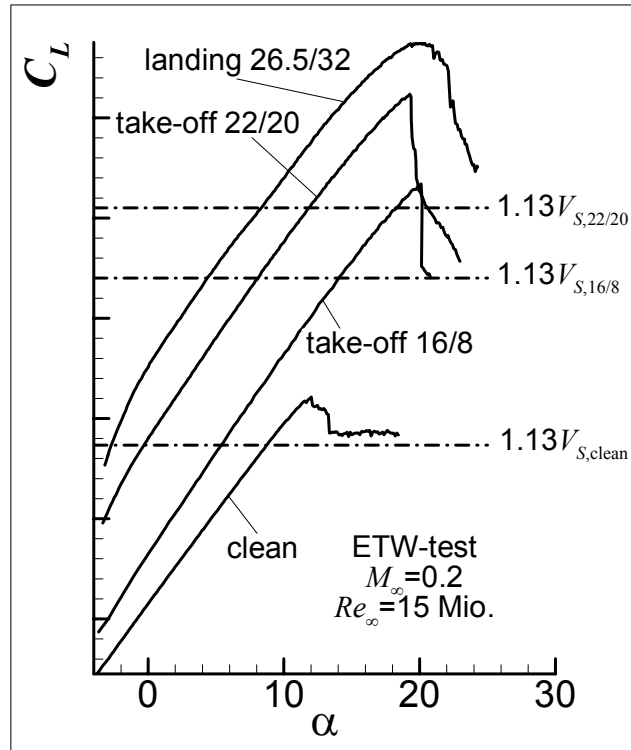

a)

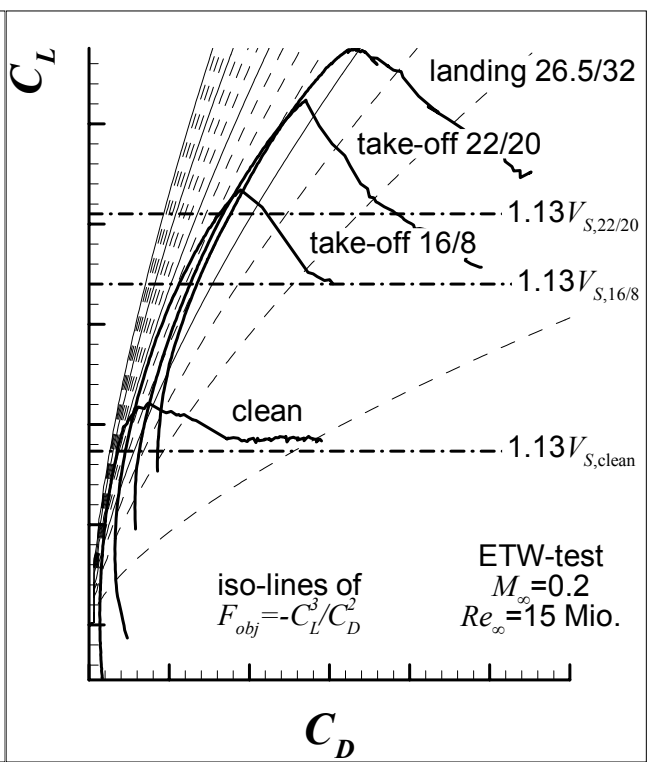

b)

Figure 6. Limits of the design range for KH3Y configuration TO2 (22/20) derived from wind tunnel data: a) lift vs. angle of attack of the reference aircraft configuration for different settings; b) lift vs. drag of the reference aircraft configuration for different settings together with the iso-lines (dashed) of the objective function; maximum lift coefficient for each setting marked with dash-dotted line. 
for the flow conditions listed in Table 2 applying standard 2D normalization of the onflow conditions. The correctness of this procedure is indicated by the match of the pressure distributions shown in Figure 7. These pressure distributions were also used by the partners to adjust their flow calculation procedures in order to obtain comparable initial conditions for the optimization.

Another focus was set on an approximation method that should allow for a reliable prediction of the 3D wing behaviour based on $2 \mathrm{D}$ or $2.5 \mathrm{D}$ (infinite swept wing) calculations. This was evident, because the flap design obtained with the $2 \mathrm{D} / 2.5 \mathrm{D}$ methods should be verified by the wind tunnel test with the 3D wing. The method chosen incorporates the assumption, that the shape of the spanwise lift and drag distribution of the $3 \mathrm{D}$ wing is unchanged due to the modifications of the flap and can be scaled based on the lift and drag improvements of the 2D wing section. This assumption is allowed for the investigated type of high-lift wing incorporating full span slat and flap. Comparison of the previously calculated 2D section data for the initial configuration and experimental data led to the relations

$$
C_{L_{3 D}}=\gamma_{C_{L}} \cdot C_{L_{2.5 D}}, \gamma_{C_{L}}=0.84173
$$

and

$$
C_{D_{3 D}}=\gamma_{C_{D}}\left(C_{D_{2,5 D}}+\frac{C_{L_{2,5 D}}^{2}}{\pi \widetilde{\Lambda}}\right), \quad \widetilde{\Lambda}=\Lambda \cdot \frac{\gamma_{C_{D}}}{\gamma_{C_{L}}^{2}}=14.3926
$$

The definition of the objective function is based on the climb index

$$
\begin{aligned}
& F_{o b j}(\boldsymbol{x})=\sum_{i=1,2} w_{i} \cdot F_{i}(\boldsymbol{x}) \\
& F_{1}(\boldsymbol{x})=-C_{L_{3 D}}^{3} /\left.C_{D_{3 D}}^{2}\right|_{\alpha=8.00^{\circ}} \\
& F_{2}(\boldsymbol{x})=-C_{L_{3 D}}^{3} /\left.C_{D_{3 D}}^{2}\right|_{\alpha=11.91^{\circ}}
\end{aligned}
$$

at the limits of the design range with equal weighting factors $w_{1}=w_{2}=0.5$. This performance indicator is better suited for high-lift performance improvement than the lift to drag ratio, because it has an additional weighting on the lift coefficient. The climb index itself is derived form the climb speed which is approximately

$$
\frac{w}{V} \approx \frac{T}{G}-\frac{C_{D}}{C_{L}} \Rightarrow w \approx \frac{1}{\sqrt{C_{L}}} \frac{T}{G}-\frac{C_{D}}{C_{L}^{3 / 2}}
$$

Constraints have to be applied to prevent loss of lift coefficient and increase of nose down pitching moment. An additional penalty

$$
P(\boldsymbol{x})=\left\{\begin{array}{rcc}
0 & \forall & \Delta x_{F} \leq 0 \\
\left|F_{o b j}\left(\boldsymbol{x}_{\text {ini }}\right)\right| \cdot\left(200 \cdot \Delta x_{F}^{2}\right) & \forall & \Delta x_{F}>0
\end{array}\right.
$$


Table 3. Classification of the methods applied by the partners for the flap design

\begin{tabular}{|c|c|c|c|c|}
\hline Partner & Solver type & Grid type & Dimension & Optimization algorithm \\
\hline A-D & panel-BL & & $3 \mathrm{D}$ & best engineering practice \\
\hline CIRA & Euler-BL & structured & $2 \mathrm{D}$ & genetic algorithm \\
\hline DLR & RANS & structured & $2 \mathrm{D}$ & $\begin{array}{l}\text { simplex algorithm } \\
\text { differential evolutionary } \\
\text { sorithm }\end{array}$ \\
\hline FOI & RANS & unstructured & $2.5 \mathrm{D}$ & quasi-Newton method \\
\hline ONERA & RANS & $\begin{array}{l}\text { structured } \\
\text { chimera }\end{array}$ & $\begin{array}{l}2 \mathrm{D} \\
2.5 \mathrm{D}\end{array}$ & conjugate gradient \\
\hline
\end{tabular}

is added to take into account weight increase of the kinematics system with larger flap deployment and was specified on industrial request.

The degrees of freedom for the design are the three degrees of freedom for the flap deflection and the part of the flap shape that is hidden when the flap is retracted.

For further identification this test case is named TC302.

\section{F. Applied methods}

Table 3 summarizes briefly the methods used by the involved partners for the design of the flap. A more complete description of the details of the methods applied on this design case has been published during the EUROGEN 05 conference ${ }^{20-23}$. Compared to the mandatory test case described earlier, additional methods were used to investigate also dependencies of the optimum solution on the calculation method.

DLR made some preliminary tests on this design case applying gradient-based, gradient free as well as stochastic methods $^{21}$. The final design was obtained using a differential evolutionary algorithm (DE) ${ }^{24}$. DE has been tested both on benchmark problems ${ }^{25}$ and on real problems ${ }^{26}$ and it often appears to be the best performing algorithm for finding the global optimum.

ONERA assessed the influence of 2D and 2.5D flow calculations by performing optimizations for the normalized wing section and for the infinite swept wing. As indicated by the mandatory test case, CIRA assessed the usability of the Euler-BL method for this design case in advance of the optimization. Because the differences of the RANS and the Euler-BL results for the baseline flap had been very small, it was again decided to use the Euler-BL approach for this design.

A-D's part of the work had been agreed to not perform numerical optimization for this design, but to apply their best engineering tools. This would allow demonstrating directly the benefits of the numerical optimization approach compared to today engineering work methods. The method A-D applied incorporates 2D panel-boundary layer method that is coupled to a $3 \mathrm{D}$ lifting line method.

\section{G. Optimization results}

All partners distributed their optimization results to including:

- aerodynamic coefficients, surface pressure distributions and flow fields of the initial and optimized configuration

- History of optimization in terms of design variables, aerodynamic coefficients, single objectives, global objective

Table 4. Summary of performed optimization calculations

\begin{tabular}{llll}
\hline \hline Partner & Design variables & Dimension & Optimization algorithm \\
\hline A-D & shape \& setting & 3D & $\begin{array}{l}\text { best engineering practice } \\
\text { genetic algorithm }\end{array}$ \\
CIRA & $\begin{array}{l}\text { setting } \\
\text { shape \& setting } \\
\text { shape \& setting }\end{array}$ & 2D & $\begin{array}{l}\text { simplex algorithm } \\
\text { differential evolutionary algorithm } \\
\text { vLR }\end{array}$ \\
& & & $\begin{array}{l}\text { variable metric method } \\
\text { quasi-Newton method } \\
\text { conjugate gradient }\end{array}$ \\
FOI & shape \& setting & 2.5D & 2D \\
ONERA & setting & $2.5 \mathrm{D}$ & \\
\hline \hline
\end{tabular}



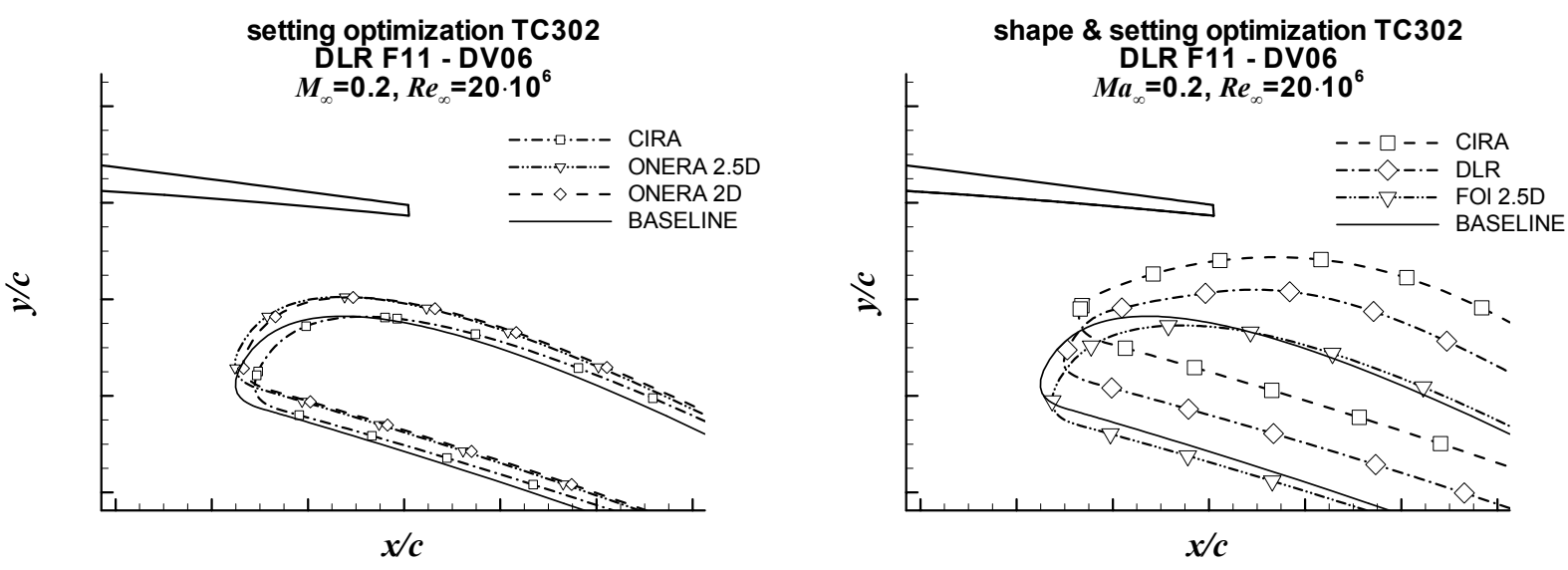

Figure 8. Designed flap settings and shapes resulting from numerical optimization

- Optimization statistics in terms of number of needed CFD calculations, CPU-time and turn-around (wall clock) time.

A work share has been agreed by the partners in order to achieve as much information on the design case as possible. It was planned that some partners (ONERA, CIRA) should focus on setting optimization and others (DLR, FOI) to investigate flap shape and setting optimization. Due to unsatisfactory results of the setting optimization CIRA decided to additionally also perform a flap shape and setting optimization. Table 4 summarizes the available data. The obtained optimum solutions are depicted in Figure 8. Table 5 lists the objective function improvements predicted by the numerical optimization method. It has to be pointed out that these values are derived from the method used within the optimization cycle and may be not directly comparable.

\section{Flap setting design}

The original ONERA setting optimization shows the largest improvements based on the optimization prediction. The difference between 2D and 2.5D calculation method is of minor importance. This verifies to some extent, that the 2D methodology is appropriate for this kind of design. The CIRA setting design shows less improvements and a different direction of setting changes. While the movement for the ONERA design is in the direction to close the gap, the CIRA design moves the flap downstream while retaining the flap gap. In both cases the flap angle is unchanged.

\section{Flap shape and setting design}

The combined shape and setting design shows an even larger variety of obtained solutions to the design problem. This is some kind of expected, since the additional parameters increase the design space and the chance of multiple locally optimal configurations. The spreading of the predicted improvements in contrast is much smaller than for the

\section{Table 5. Summary of obtained take-off performance improvements predicted by optimization methods}

\begin{tabular}{llll}
\hline \hline Partner & Design variables & Dimension & Objective improvement \\
\hline CIRA & setting & 2D & $\Delta F_{o b j}=1.44 \%$ \\
& shape \& setting & & $\Delta F_{o b j}=2.54 \%$ \\
ONERA & setting & 2D & $\Delta \mathrm{F}_{\text {obj }}=8.17 \%(1.69 \%)^{*}$ \\
& & 2.5D & $\Delta \mathrm{F}_{\text {obj }}=7.49 \%(1.22 \%)^{*}$ \\
DLR & shape \& setting & 2D & $\Delta F_{o b j}=1.97 \%$ \\
FOI & shape \& setting & 2.5D & $\Delta F_{o b j}=0.9 \%$ \\
A-D & best practice & 3D & $\Delta F_{o b j}=0 \%$ \\
\hline \hline
\end{tabular}

(*): Final values - see chapter $\mathrm{H}$

pure setting design mentioned before. First setting optimizations carried out by ONERA predicted a much larger improvement than all the shape and setting designs. This indicated a large dependency of the improvements on flow solving procedure, especially on drag evaluation. New results obtained by ONERA with adapted numerical setups (values in italics in Table 5) lead to an improvement lower than when considering both shape and setting. An 


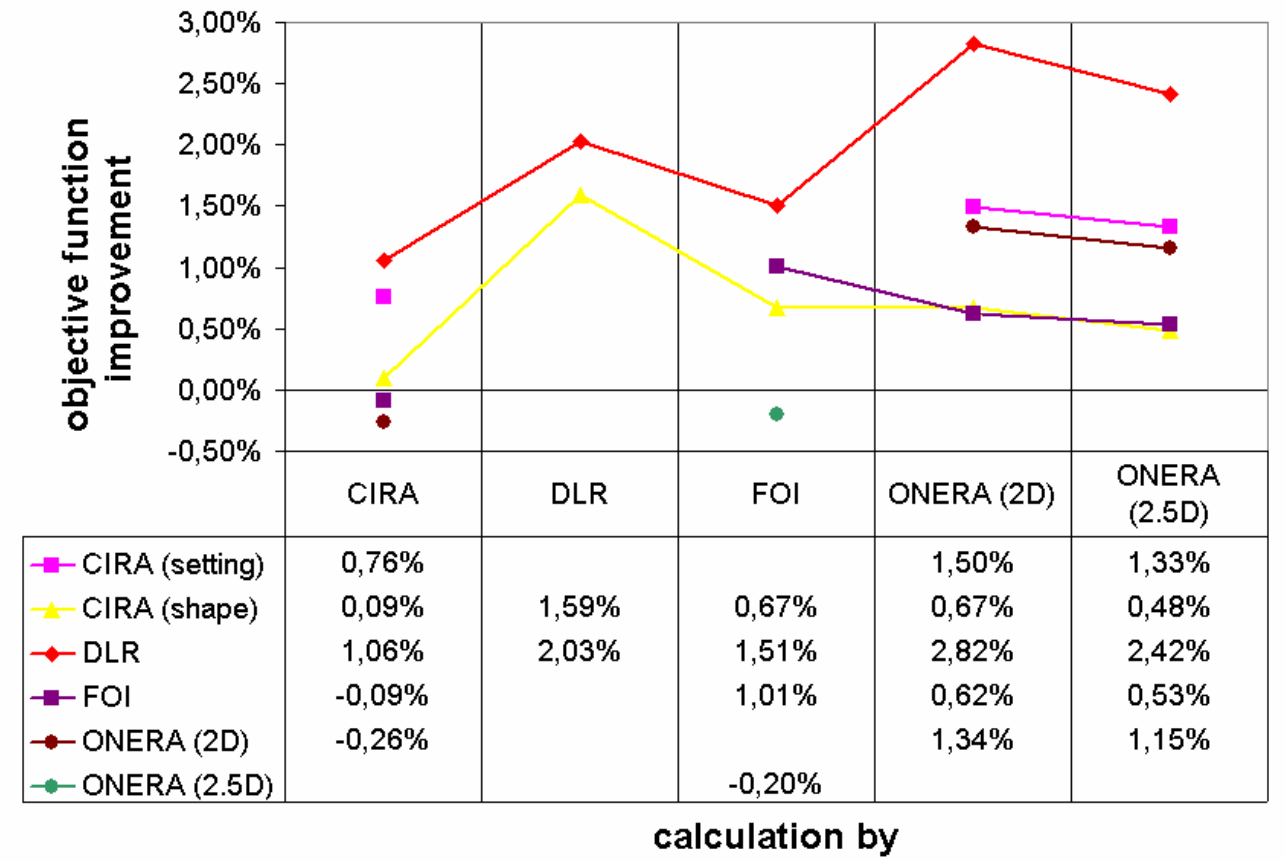

Figure 9. Comparison of improvements resulting of cross-calculations of the different partners

interesting side effect for the shape and setting design is observed when virtually connecting the leading edges of all three designs. It is seen that the leading edges lie almost on a straight line indicating an optimum correlation of gap and overlap when changing the shape.

\section{Best engineering practice}

The major conclusion form best engineering practice design is a failure of improving the performance while taking into account the constraints. An improvement of the take-off performance was only achievable when violating either the lift or pitching moment constraints. This result is not as astonishing, since the baseline has been formerly designed using these methods.

\section{H. Cross-checking of optimization results and selection for wind tunnel entry}

As seen from the results it is necessary to compare the different design optimization results with the same flow solving procedure in order to be able to judge about the best obtained results. For this reason the cross-calculation of the results was implemented in the work programme. Within these cross-calculations different partners calculate the design optimization results from other partners. By this a set of results are achieved that allows eliminating the dependencies of the result on the solving procedure. This is a prerequisite to be able to select the best obtained design for wind tunnel testing.

A common request for these calculations was to use the highest level of simulation accuracy. For this reason CIRA recomputed all configurations using their RANS solver instead of the Euler-BL solver applied for the optimization. DLR delivered their results computed on the finest mesh level instead of the second multigrid level as used in the design.

The first comparison showed a good agreement of the tendencies between the different results for all partners excepting ONERA. Their tendencies showed much bigger differences and other tendencies between the configurations. In the further proceeding of the task work ONERA proved their computational setup and detected some difficulties in the original setup that have been responsible for this behavior. So ONERA adjusted their CFD calculation methods in terms of chimera grid generation, use of preconditioning and the selection of the turbulence model, which is responsible for the changed values. After refinement of the setup ONERA also repeated the optimization. These new results are given in italic in Table 5. The negligible difference between 2D and 2.5D calculation remained unaffected, but now the difference between both is for the gap value and no longer for the overlap value. 


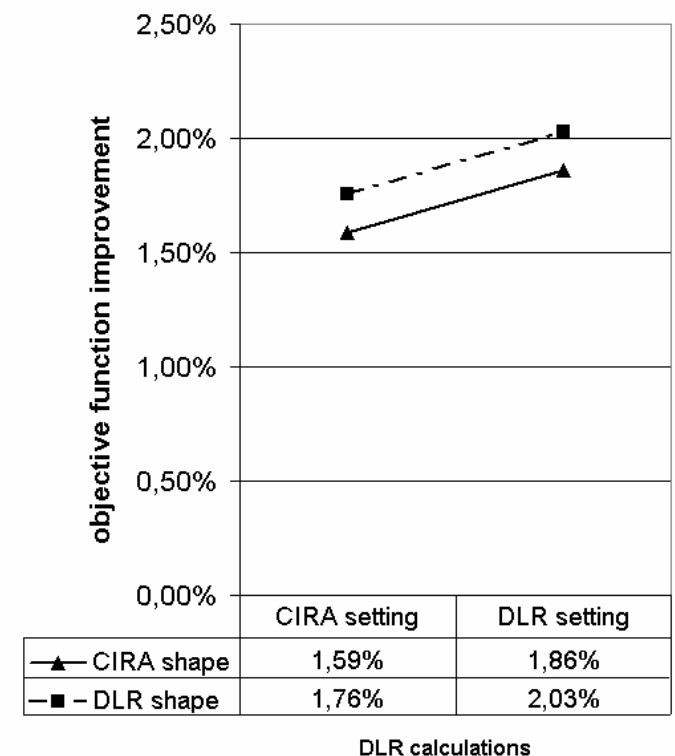

Figure 10.Breakdown of improvements of CIRA and DLR designs on shape and setting effects based on DLR calculations

performed for the comparison of DLR and CIRA flap

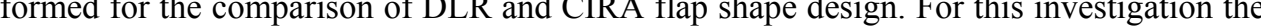
has been positioned at the setting of the other one. As an example Figure 10 shows performance improvements without the geometric penalty according to DLR calculations for the two shapes at the two settings. There is only a slight advantage for the DLR flap shape predicted. This result is underlined when comparing the shape and the pressure distribution for the same setting, as it is depicted in Figure 11. The difference between both shapes is visible only in a small part of the flap suction peak. This comparison shows that both flap shapes are equivalent and the differences might have their major reason in the differences of the flap shape parameterization applied by the partners for this study.

This result raises the question if the small dependence of the aerodynamic behavior on the large variation of the flap setting is artificial to the computations or can be proven experimentally. For this reason it was finally decided not to investigate the optimum setting for the baseline flap shape in the wind tunnel test. Instead it was decided to test the new flap with the flap shape designed by DLR at the two settings resulting form DLR and CIRA flap shape and setting design.

\section{ETW wind tunnel verification}

In order to verify the design optimization results obtained from numerical simulations a wind tunnel test has been conducted. In order to be as close as possible to future industrial needs, the optimization has been performed for high Reynolds numbers. For this reason for the wind tunnel test an entry in the European transonic wind tunnel facility (ETW) had been planned from the beginning. The test for the verification of the design optimization work of this task has been performed in May 2006.

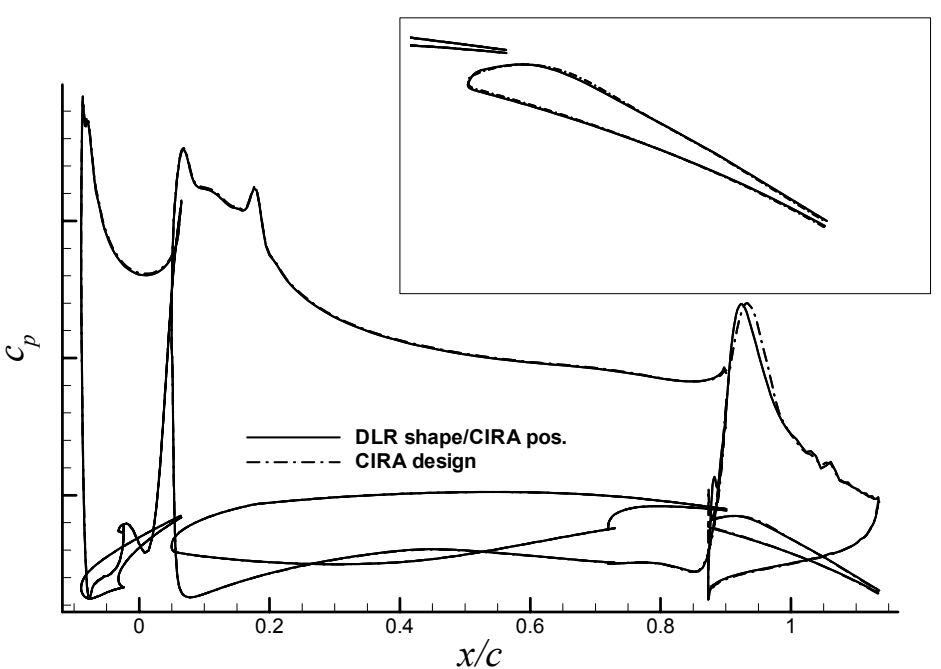

Figure 11.Comparison of CIRA and DLR flap shape designs at the same setting and comparison of corresponding pressure distributions 


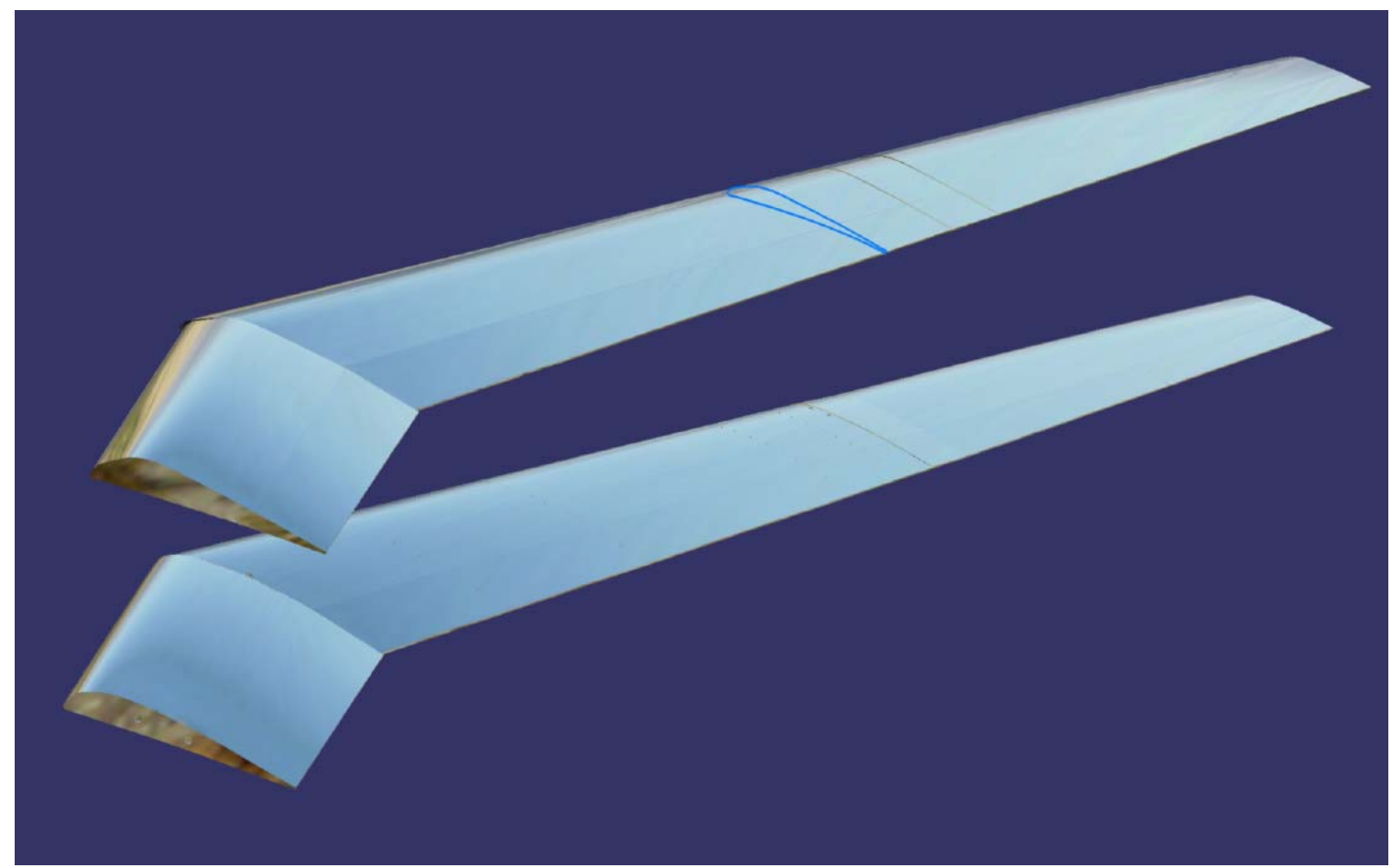

Figure 12.Comparison of original 3D model flap (lower) and newly designed model flap (upper); blue line: designed flap section

TO 2 flap setting modell KH3Y EUROLIFT II Task 2.2

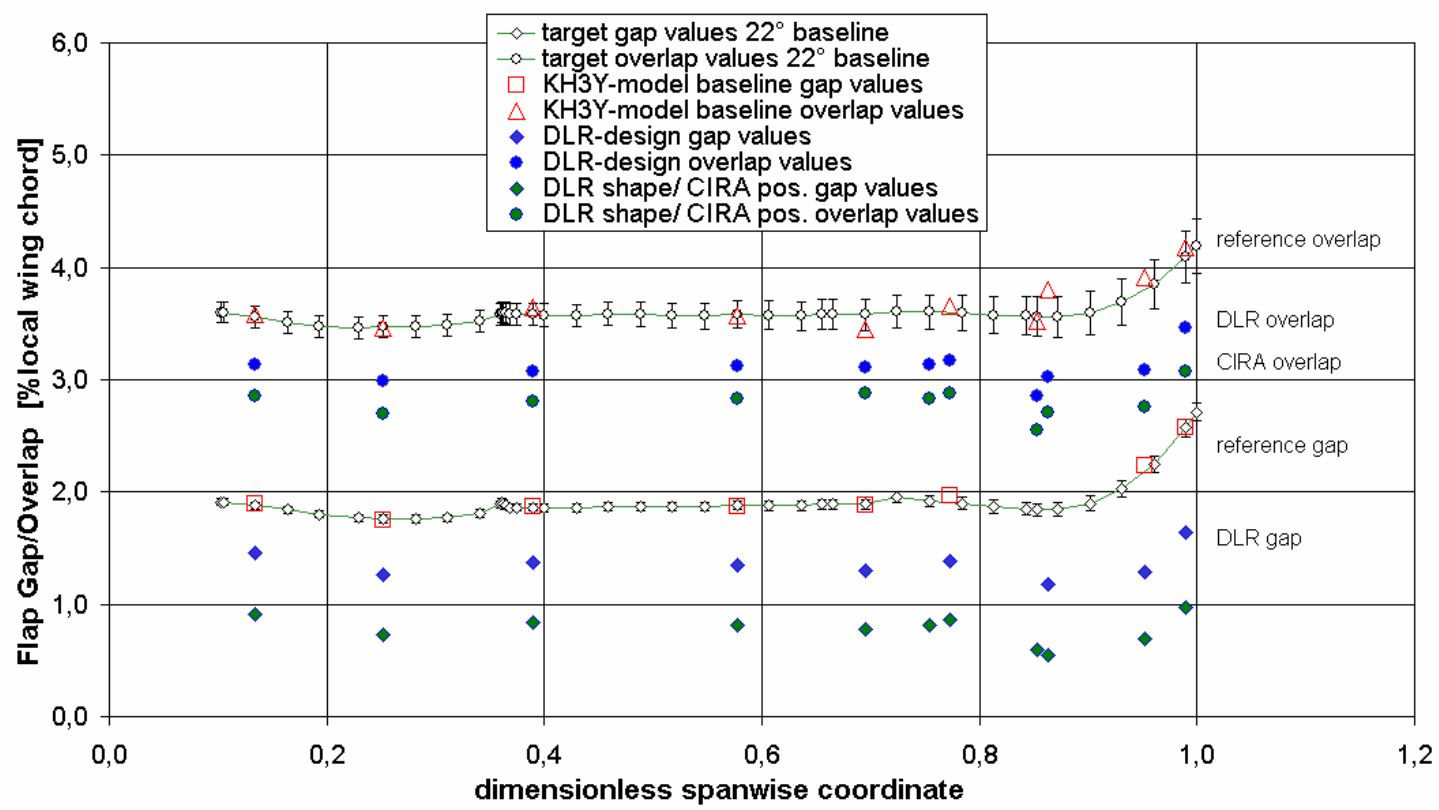

Figure 13.Setting distribution along wing span of the KH3Y model compared for the original flap and the newly designed flap at both setting positions, evaluated with six-component coordinate measurement equipment.

American Institute of Aeronautics and Astronautics 


\section{Wind tunnel model setup}

At first, the selected flap shape design has been applied to the KH3Y wind tunnel model. Since the design investigations have all been for one 2D wing section only, first this shape has to be transferred to the 3D flap of the model. This work has been done using the CAD software CATIA (V4). The software offers a wide range of lofting functions, ideally usable for this issue. For this lofting the original flap shape has been divided on the upper and lower part to limit the modifications of the shape to the allowed range. Afterwards the designed flap shape has been transformed to other wing sections (kink, root and tip) by scaling the length to the local flap chord and the thickness relate to the local section thickness by affine transformation rules. Figure 12 shows a comparison of the original and newly designed 3D model flap. The blue line in the figure shows the designed flap section. By the design method it has been guaranteed that the flap shape is exactly met for the design section and the characteristics of the shape are maintained along the whole flap span. The position of the new flap for both settings has been transferred to the 3D model related to the local flap chord, resulting in the most uniform setting distribution. By this also the characteristics of the setting is also maintained for the whole wing. Figure 13 shows the realized distribution of the setting values gap and overlap along the wing span of the KH3Y model, which have been measured with a sixcomponent coordinate measurement equipment. For measurement purposes the new flap was equipped with pressure tab rows in four wing sections, including the design wing section DV06.

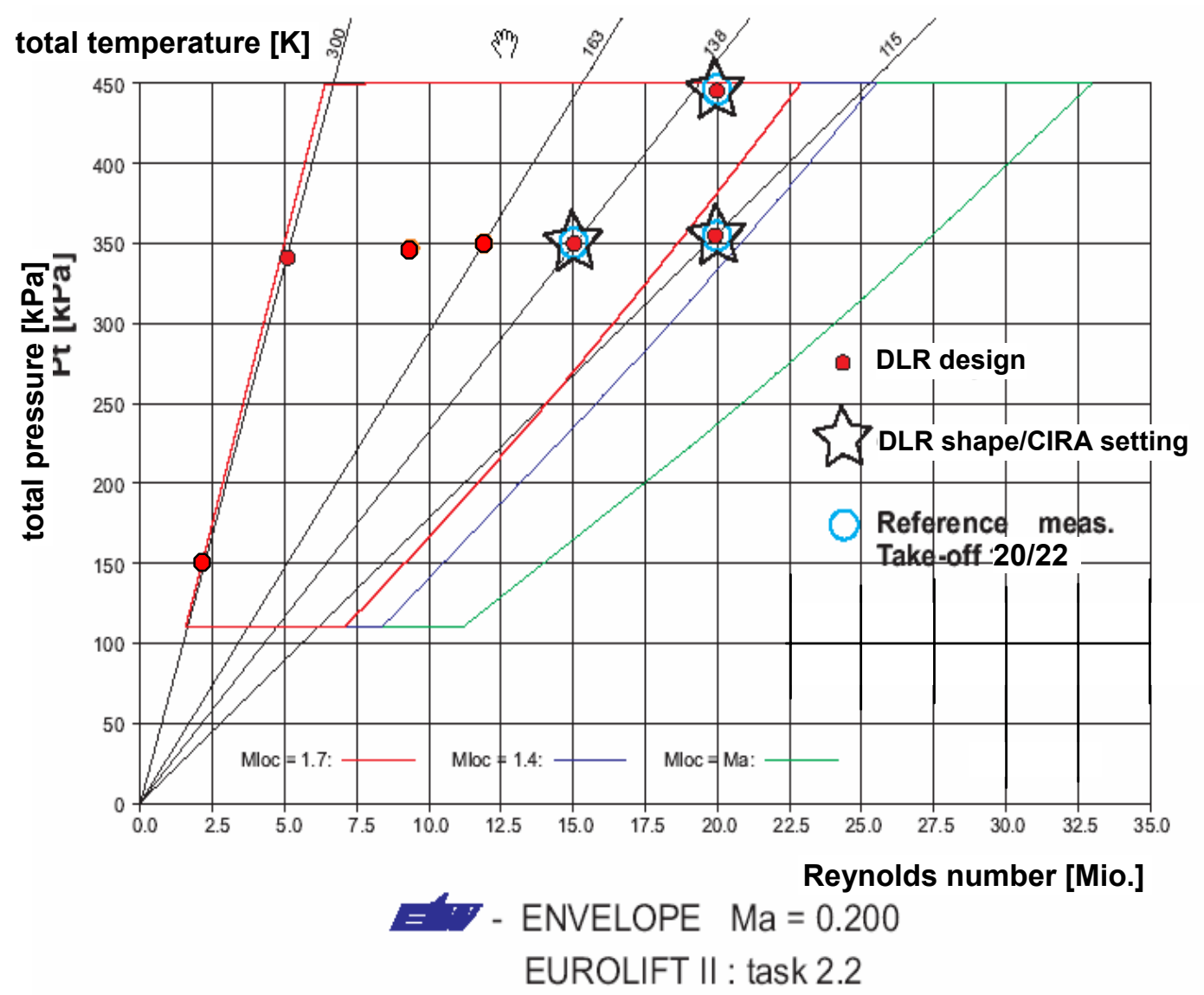

Figure 14.Flow conditions investigated during the ETW wind tunnel entry for verification of the task 2.2 flap design

\section{J. Wind tunnel test programme}

Measurements have been conducted in ETW for all three configurations (denoted baseline, DLRopt and CIRAset) at three wind tunnel conditions (Figure 14). The three major tunnel conditions cover two different Reynolds numbers: i) $R e_{\infty}=15$ Mio., in order to be able to compare to former EUROLIFT (I) data, and ii) $R e_{\infty}=20$ Mio. corresponding to the design case description. The Reynolds number variation from 15 to 20 Mio. has been obtained by a variation of stagnation temperature $\left(T_{\mathrm{t}}=138 \mathrm{~K}\right.$ and $T_{\mathrm{t}}=115 \mathrm{~K}$ at $\left.p_{\mathrm{t}}=3.5 \mathrm{bar}\right)$ and pressure $\left(p_{\mathrm{t}}=3.5 \mathrm{bar}\right.$ and 
$p_{\mathrm{t}}=4.5$ bar at $T_{\mathrm{t}}=138 \mathrm{~K}$ ) independently. With this test programme it is afterwards possible to distinguish clearly between Reynolds number effects and the influence of model deformations due to the pressurized tunnel. The DLRopt has been tested at additional points during the warm-up of the tunnel to ambient conditions at the end of the wind tunnel test entry. All measurements have been preformed at the same Mach number $M_{\infty}=0.2$.

\section{K. Assessment of optimization results with wind tunnel data}

Out of the lot amount of data within this report a focus is laid on a comparison of the wind tunnel data of the ETW entry and the CFD prediction during the numerical design work. First of all the achieved improvement of the new flap design has been analyzed. Figure 15 shows the relative improvement of the aerodynamic part of the optimization objective, neglecting the constraints, compared to the scaled CFD predictions resulting from the crosscalculations (including ONERA's refined solution procedure). All the computationally predicted improvements generally show a very good agreement with the values obtained experimentally for the $3 \mathrm{D}$ half model. Also the slope between the two design points is pretty good captured. Nevertheless there are slight differences in the prediction between the both settings for the newly designed flap, depending on the partners' computational methods. On the other side these differences are of similar order of magnitude as the scatter within the wind tunnel data. Remembering, that the cross-computations have been performed for the original CIRA flap shape design, except for one DLR calculation, this also verifies the equivalence of the CIRA and DLR flap shapes.

In Figure 16 an exemplary comparison of the pressure distributions on the flap is shown at the first design point $\alpha=8^{\circ}$ for the design wing section DV06. For the baseline only the DLR computation is plotted for comparison. The computations labelled CIRA design have been performed also on the CIRA shape in contrast to the measurements made with the DLR shape. The comparison shows the spreading of the predictions of the flap flow and the flap suction peak is slightly under predicted. Nevertheless the change in the characteristics of the flap pressure distribution is well captured. Also the response of the wing pressure distribution on the change of flap shape and position agrees very well between computations and measurements. This verifies that the improvements observed in the wind tunnel are due to the flap shape and setting design and no artificial side effects from somewhere else at the $3 \mathrm{D}$ wing.

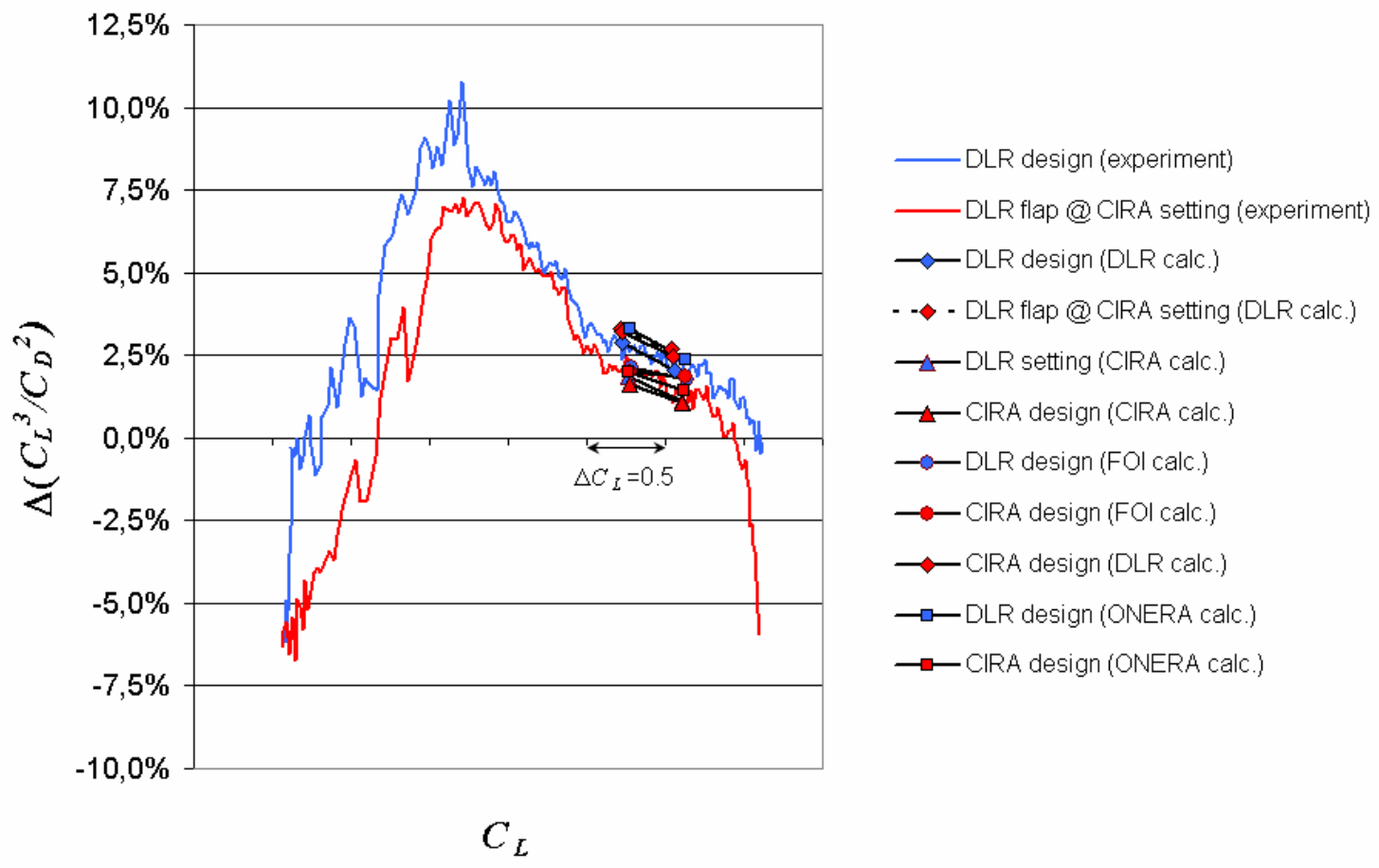

Figure 15.Comparison of predicted relative improvement of aerodynamic performance compared to wind tunnel data 


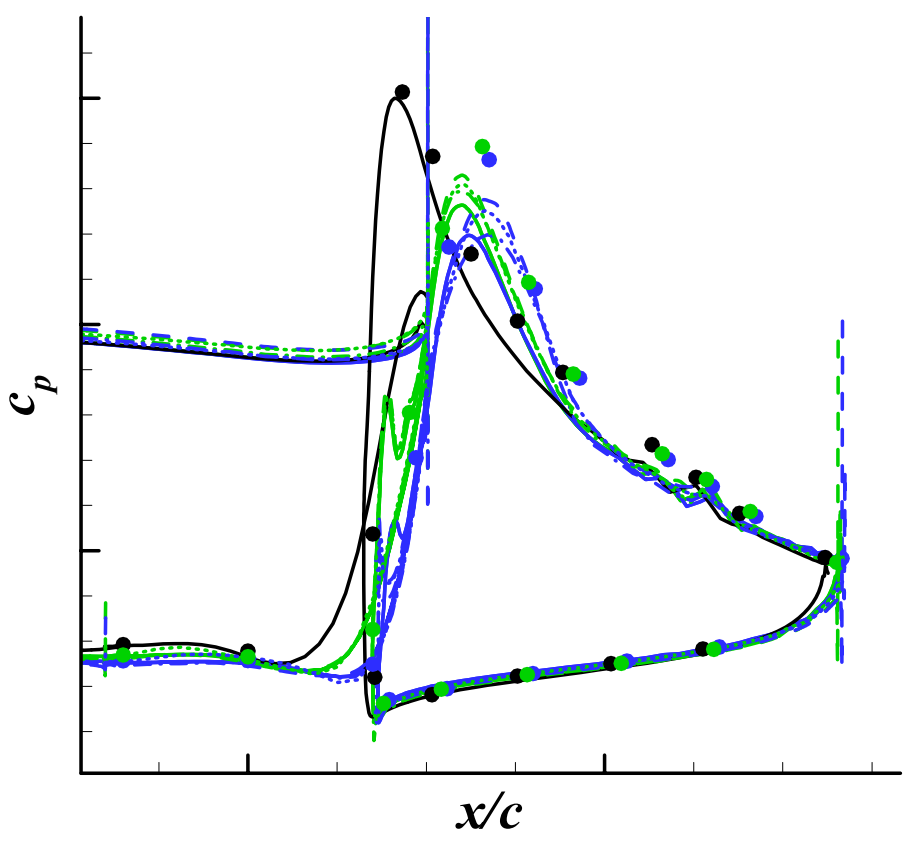

\section{KH3Y -DV06 wing section \\ $M_{\infty}=0.20$ \\ $\alpha=8^{\circ}$}

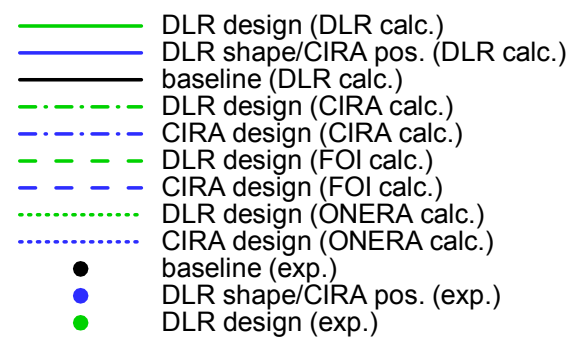

Figure 16.Comparison of numerically predicted and experimentally measured pressure distributions on the flap for the newly designed flap in both investigated setting positions at the first design point for the design wing section DV06

\section{Summary}

The objective of EUROLIFT II task 2.2 was the demonstration of the applicability of design methods based on computational fluid dynamics and numerical optimization methods for the design of high-lift systems for transport aircraft. A first study on a mandatory 2D design case showed the readiness of the methods as well as some limitations of the range of design issues to be addressed.

Based on this experience a design study for take-off performance improvement for the wing of the KH3Y model was performed, based on $2 \mathrm{D}$ and $2.5 \mathrm{D}$ wing section design. Special care has been taken for the setup of the calculations in order to be comparable to behaviour of the 3D wing. A detailed transformation method has been derived for this purpose to approximate the improvements of the 3D wing based on the 2D/2.5D CFD predictions. The later results approved the validity of this approach for the performance prediction of the investigated type of high-lift system with full span slats and flaps.

The design has been performed at one wing section of the designated KH3Y model at two design points and a high Reynolds number related to real aircraft flight conditions. In order to make the best selection for wind tunnel verification all results of the numerical deign optimizations of the different partners have been cross-computed to eliminate dependencies of the result on the numerical setup of the design method. This additionally led in one case to an improved numerical setup for design optimization calculations.

The finally selected design has been carefully transferred to the 3D model flap using modern CAD systems. Special care has been taken to maintain the flap shape and setting characteristics of the design wing section along the whole wing span. Resulting from the cross-calculations the new flap shape has been investigated at two different settings, which had been predicted to gain similar improvements. Measurements have been performed in ETW cryogenic transonic wind tunnel facility at different Reynolds numbers, including the design Reynolds number, in order to additionally account for Reynolds number and model deformation effects.

The comparison of numerically predicted improvements with experimental data shows an astonishing agreement. Detailed insight into flow properties by means of pressure distributions shows that the numerical methods are able to capture the physics responsible for the performance improvement. This result suggests that numerical optimization based on CFD can benefit the design of aircraft high-lift devices. 


\section{Acknowledgements}

The work reported here has been funded by the European Commission within the $6^{\text {th }}$ Framework Programme under contract no. AST 2004 502896. The authors want to mention Ralf Mertins, Airbus Germany, who performed the activities related to Airbus' participation, but was not able to contribute to this paper as an author. CIRA wishes to thank Prof. Mark Drela for allowing the use of his MSES code in its research work.

\section{References}

${ }^{1}$ Hansen, H. , Thiede, P., Moens, F., Rudnik, R. and Quest, J., "Overview About the European High Lift Research Programme EUROLIFT," 42nd AIAA Aerospace Sciences Meeting and Exhibit, Reno, AIAA Paper 2004767, 2004.

${ }^{2}$ Gerhold, T. and Evans, J., "Efficient Computation of 3D-Flows for Complex Configurations with the DLR-Tau Code Using Automatic Adaptation," Notes on Numerical Fluid Mechanics, edited by W. Nitsche, H.-J. Heinemann, and R. Hilbig, Vol. 72, Vieweg Braunschweig, 1998, pp. 178-185.

${ }^{3}$ Drela, M., A User's Guide to MSES 2.95, MIT Computational Aerospace Sciences Laboratory, Sept. 1996.

${ }^{4}$ Kroll, N., Rossow, C.C., Becker, K. and Thiele, F., "The MEGAFLOW project," Aerospace Science and Technology, Vol. 4, No. 4, 2000, pp. 223-237.

${ }^{5}$ Brodersen, O., Hepperle, M., Ronzheimer, A., Rossow, C.-C. and Schöning, B., "The Parametric Grid Generation System MegaCads," 5th International Conference on Numerical Grid Generation in Computational Field Simulation, edited by B.K. Soni, J.F. Thompson, J. Häuser and P. Eisemann, National Science Foundation, 1996, pp. 353-362.

${ }^{6}$ Eliasson, P., "EDGE, A Navier-Stokes Solver for Unstructured Grids," FOI-R-0298-SE, Swedish Defence Research Agency, Stockholm, November 2001.

${ }^{7}$ Amoignon, O., Pralits, J.O., Hanifi, A., Berggren, M. and Henningson, D.S., "Shape optimization for delay of laminar-turbulent transition," AIAA Journal, Vol. 44, No. 5, 2006, pp. 1009-1024.

${ }^{8}$ Gazaix, M., Jolles, A. and Lazareff, M., "The elsA Object-Oriented Computational Tool for Industrial Applications," 23rd Congress of ICAS, September 2002, Toronto (Canada).

${ }^{9}$ Wilcox, D., "Simulation of Transition with a Two-Equation Turbulence Model," 25th AIAA Fluid Dynamics Conference, AIAA Paper 94-2386, June 1994.

${ }^{10}$ Goncalves, E., and Houdeville, R., "Reassessment of the Wall Function Approach for RANS Computations," Aerospace Science and Technology, Vol. 5, No. 1, 2001, pp. 1-14.

${ }^{11}$ Eliasson, P., "CFD Improvements for High-Lift Flows in the European Project EUROLIFT," 21st AIAA Applied Aerodynamics Conference, AIAA Paper 03-3795, June 2003, Orlando (Florida).

${ }^{12}$ Vicini, A., and Quagliarella, D., "Inverse and Direct Airfoil Design Using a Multiobjective Genetic Algorithm," AIAA Journal, Vol. 35, No. 9, 1997, pp. 1499-1505.

${ }^{13}$ Vicini, A. and Quagliarella, D., "Airfoil and Wing Design Through Hybrid Optimization Strategies," AIAA Journal, Vol. 37, No. 5, 1999, pp. 634-641.

${ }^{14}$ Frommann O., Synaps Pointer Pro V2.50, Synaps Ingenieur-Gesellschaft mbH, Bremen, Germany 2002.

${ }^{15}$ Rowan, T., "Functional Stability Analysis of Numerical Algorithms," PhD-Thesis, Department of Computer Sciences, University of Texas at Austin, 1990.

${ }^{16}$ Nocedal, J. and Wright, S., Numerical Optimization, Springer Series in Operations Research, 1999.

${ }^{17}$ Vanderplaats, G.N., "CONMIN - for constrained function minimisation," NASA TMX 62282, 1973.

${ }^{18}$ Wild, J., Mertins, R., Quagliarella, D., Brezillon, J., Germain, E., Amoignon, O. and Moens, F., "Realistic high-lift design of transport aircraft by applying numerical optimization", ECCOMAS CFD 2006 Conference, proceedings on CD-ROM, TU Delft, Paper-No. 191, 2006.

${ }^{19}$ Federal Aviation Administration, "Airworthiness standards: Transport category airplanes," Federal Aviation Regulations, FAR Part 25, 2006.

${ }^{20}$ Amoignon, O. et. al.: "Toward optimal flap design for take-off performance," Proceedings of Evolutionary and Deterministic Methods for Design, Optimization, and Control with Applications to Industrial and Societal Problems EUROGEN 2005, edited by R. Schilling, W. Haase, J. Périaux, H. Baier and G. Bugeda, FLM, ISBN: 300-017534-2, Munich, 2005.

${ }^{21}$ Brezillon, J., Wild, J., "Evaluation of different optimisation strategies for the design of a high-lift flap device," Proceedings of Evolutionary and Deterministic Methods for Design, Optimization, and Control with Applications to Industrial and Societal Problems EUROGEN 2005, edited by R. Schilling, W. Haase, J. Périaux, H. Baier and G. Bugeda, FLM, ISBN: 3-00-017534-2, Munich, 2005. 
${ }^{22}$ Moens, F.: "Numerical Optimisation of the Flap Position of a Three-Element High-Lift Airfoil in 2D and 2.5D Flow using Navier-Stokes Solver, ONERA," Proceedings of Evolutionary and Deterministic Methods for Design, Optimization, and Control with Applications to Industrial and Societal Problems EUROGEN 2005, edited by R. Schilling, W. Haase, J. Périaux, H. Baier and G. Bugeda, FLM, ISBN: 3-00-017534-2, Munich 2005

${ }^{23}$ D. Quagliarella and P.L. Vitagliano, "Evolutionary Optimization of the EUROLIFT II take-off Design Case," Proceedings of Evolutionary and Deterministic Methods for Design, Optimization, and Control with Applications to Industrial and Societal Problems EUROGEN 2005, edited by R. Schilling, W. Haase, J. Périaux, H. Baier and G. Bugeda, FLM, ISBN: 3-00-017534-2, Munich, 2005.

${ }^{24}$ Storn, R. and Price, K., "Differential Evolution - a Simple and Efficient Adaptive Scheme for Global Optimization over Continuous Spaces," Technical Report TR-95-012, International Computer Science Institute, Berkley, 1995.

${ }^{25}$ Vesterstrøm, J. and Thomsen, R., "A Comparative Study of Differential Evolution, Particle Swarm Optimization, and Evolutionary Algorithms on Numerical Benchmark Problems", Proceedings of the 2004 Congress on Evolutionary Computation, Vol. 2, 2004, pp. 1980-1987.

${ }^{26}$ Ursem, R.K. and Vadstrup, P., "Parameter Identification of Induction Motors using Differential Evolution," Proceedings of the Fifth Congress on Evolutionary Computation (CEC-2003), edited by McKay et al., 2003, pp. 790-796. 